NASATTM-- $1998-208213$

RESPONSE OF COMPOSITE FUSELAGE SANDWICH SIDE PANELS SUBJECTED TO INTERNAL PRESSURE AND AXIAL TENSION

\author{
Marshall Rouse and Damodar R. Ambur \\ NASA Langley Research Center \\ Hampton, VA \\ Bernard Dopker \\ Boeing Commercial Airplane Company \\ Seattle, WA \\ Bharat Shah \\ Lockheed-Martin Aeronautical Systems Company \\ Marietta, GA
}

\begin{abstract}
Presented at the AIAAASME/ASCE/AHS/ASC 35th Structures, Structural Dynamics, and Materials Conference Long Beach, California
\end{abstract}

April 20-23, 1998

AIAA Paper No. 98-1708 


\title{
RESPONSE OF COMPOSITE FUSELAGE SANDWICH SIDE PANELS SUBJECTED TO INTERNAL PRESSURE AND AXIAL TENSION
}

\author{
Marshall Rouse* and Damodar R. Ambur ${ }^{\dagger}$ \\ NASA Langley Research Center \\ Hampton, VA \\ Bernard Dopker ${ }^{\ddagger}$ \\ Boeing Commercial Airplane Company \\ Seattle, WA \\ Bharat Shah ${ }^{\S}$ \\ Lockheed-Martin Aeronautical Systems Company \\ Marietta, GA
}

\begin{abstract}
The results from an experimental and analytical study of two composite sandwich fuselage side panels for a transport aircraft are presented. Each panel has two window cutouts and three frames and utilizes a distinctly different structural concept. These panels have been evaluated with internal pressure loads that generate biaxial tension loading conditions. Design limit load and design ultimate load tests have been performed on both panels. One of the sandwich panels was tested with the middle frame removed to demonstrate the suitability of this two-frame design for supporting the prescribed biaxial loading conditions with twice the initial frame spacing of 20 inches. A damage tolerance study was conducted on the two-frame panel by cutting a notch in the panel that originates at the edge of a cutout and extends in the panel hoop direction through the window-belt area. This panel with a notch was tested in a combined-load condition to demonstrate the structural damage tolerance at the design limit load condition. Both the sandwich panel designs successfully satisfied all desired load requirements in the experimental part of the study, and experimental results from the two-frame panel with and without damage are fully explained by the analytical results. The results of this study suggest that there is potential for using sandwich structural concepts with greater than the usual 20-in.-wide frame spacing to further reduce aircraft fuselage structural weight.

\section{Introduction}

The potential for cost and weight reduction offered by composite-facesheet sandwich structures in aircraft fuselage side panels is currently being investigated

* Senior Aerospace Engineer, Structural Mechanics

Branch. Senior Member, AIAA.

$\dagger$ Assistant Head, Structural Mechanics Branch. Associate Fellow, AIAA.

$\ddagger \quad$ Specialist Engineer, Technology and Product Development Group.

\& Senior Staff Engineer, Advanced Structures and Materials Division, Associate Fellow, AIAA.

Copyright $\mathrm{C} 1998$ by the American Institute of Aeronautics and Astronautics, Inc. No copyright is asserted in the United States under title 17, U.S. Code. The U.S. Government has a royalty-free license to exencise all rights under the copyright claimed berein for governmental purposes. All other rights are reserved by the copyright owner.

in the airframe industry. Structural trade studies for sandwich concepts that use advanced material placement methods, such as tow placement for skin and three-dimensional braiding for frames, have identified a 25 percent cost and weight reduction compared to conventional integrally-stiffened metallic structures (Ref. 1). Sandwich structures offer additional potential for weight reduction by decreasing the number of frames by increasing the fuselage frame spacing. Sandwich structures are good candidates for implementing greater frame spacing than the usual 20 to 22 in. since skin panels for these structures have much higher bending stiffnesses than the more conventional stringer-frame stiffened skins with minimum gauge thicknesses. The sandwich panels described in the present paper utilize two leading structural concepts and have been designed to generate preliminary performance information for sandwich structures. One of the panels has been tested
\end{abstract}


with twice the usual fuselage frame spacing and a notch at the window-belt region.

The design studies for the curved panel described in the present paper utilized existing tension fracture data for flat sandwich panels which could result in conservative structural designs. An important aspect of designing aircraft structures is understanding the response of undamaged and damaged sandwich structures when they are subjected to combined loading conditions that are representative of the actual operating flight environment. Very limited information currently exists for curved composite sandwich panels with damage at critical locations and subjected to combined-loading conditions. To understand better the structural behavior of a sandwich fuselage side panel with windows and with damage at a highly stressed location, biaxial tension tests have been performed by subjecting one of the damaged panels to internal-pressure loading conditions.

Finite element analyses were performed on the sandwich panels assembled in the test machine and subjected to different test loading conditions. Inplane stress and strain results for an infinitely long composite flat plate with an elliptical cutout are compared with finite element analytical results to help explain the stress gradients near the cutout in the panel. The finite element analytical results are compared with experimental results for corresponding loading conditions. The experimental results and their correlation with the analytical results are discussed in the present paper.

\section{Test Panels and Test Description}

The sandwich fuselage panels considered in the present study have three frames and have overall dimensions of a 122 -in. radius, a 72 -in. length, and a 63 -in. arc width. Each of these panels have two window cutouts, one located midway between the center frame and each of the outer frames. The elliptical window cutouts are 19.92-in. long in the fuselage circumferential direction and 15.30-in. long in the fuselage longitudinal direction. The sandwich panel facesheets were fabricated from Hercules, Inc. AS4/8552 graphite-epoxy material and the core is made from a Hexcel Korex honeycomb material. The facesheet utilizes tow-placed inner plies and fabric outer layers. The fuselage frames and window frames were fabricated from fiber preforms consisting of triaxially braided AS4 graphite fibers impregnated with 3M Company PR500 epoxy resin using a Resin Transfer Molding (RTM) process and autoclave cured. The sandwich skin and the precured frames were cocured in a single stage. Typical material properties for the tow placed, fabric, and triaxially braided AS4/8552 and AS4/PR500 graphite-epoxy material systems are presented in Table 1.
Typical construction details of the test panels are shown in Figure 1 using cross-sectional views. The cross-sectional views in Figures 1(b) and 1(c) illustrate details of the panels in the window region. For the Panel 1 cross-sectional view in Figure 1(b), the sandwich core is contoured on both the concave and convex sides of the panel to accommodate $45^{\circ}$ plies added to the 8-ply-thick facesheet near the window region. When cured, the sandwich panel has a constant inner and outer mold line radius resulting in a uniform total thickness throughout the skin. The cross-sectional view shown in Figure 1(c) illustrates details of the Panel 2 window region. This sandwich panel is made of 18-ply facesheets and the sandwich core is terminated in the window region by tapering the core of the inner surface to form a 36-ply-thick laminate in the window region. The core is also potted with an epoxy closeout in the tapered region. When cured, sandwich Panel 2 has a non-constant inner mold line radius and a reduced skin thickness in the window region of the panel. For both panel concepts, graphiteepoxy doublers fabricated from preimpregnated fabric were cocured at the curved and flat edges of the panel to introduce the axial and hoop loads into the panel skin. A photograph of the a test panel is shown in Figure 2.

To evaluate the sandwich panel designs, combined load tests were performed on the two undamaged panels in a pressure-box test machine (Ref. 2). In the undamaged condition, the panels were subjected to an internal pressure condition of $18.2 \mathrm{psi}$ with the corresponding axial load; and a combined load condition with $13.65 \mathrm{psi}$ of internal pressure and $2,450 \mathrm{lb} / \mathrm{in}$. of axial tension. The undamaged test conditions were also applied to Panel 1 with its center frame removed to gather preliminary structural performance information for a panel with twice the initial frame spacing. A notch was then cut in Panel 1 along the hoop direction starting at the window and extending through the window frame and the skin. The panel was loaded to the design limit load condition of $8.85 \mathrm{psi}$ of internal pressure and $1,630 \mathrm{lb} / \mathrm{in}$. of axial tension. The panels were instrumented with electrical resistance strain gages to record strains and with displacement transducers to monitor panel displacements.

\section{Finite element models}

The finite element model of Panel 1 in the pressure-box test machine is shown in Figure 3. The sandwich panel is modeled using the ABAQUS finite element analysis program (Ref. 3) with 4-node isoparametric elements for the facesheets and three 8-node solid elements through-the-thickness to represent the honeycomb core. The ply drop-offs in the facesheets are discretely modeled to represent the thickness changes appropriately. 
The circumferential frames and the window frames are also modeled using the 4-node shell elements. The window glazing is also modeled using shell elements. Only reaction forces along the edges perpendicular to the window glazing are transmitted to the window frame. It is assumed that no inplane forces are transmitted to the panel by the window glazing.

The hoop and axial load introduction plates of the test fixture are modeled with shell elements. Since symmetry boundary conditions are assumed at the axial and hoop centerlines, only a quarter of the structure is modeled and analyzed. Along the sandwich panel hoop direction, the test fixture hoop-load-reaction turnbuckles for the skin and frames are represented with the appropriate length and stiffnesses to model the panel boundary conditions properly. Axial load is applied to the beams representing the hydraulic actuators attached to the axial load introduction plates. The quarter model of the test panel in the pressure box has a total of 5,343 elements and approximately 26,650 degrees of freedom. Geometric nonlinear analyses have been performed for all load cases considered in the present paper. Similar modeling and analysis efforts were conducted for Panel 2 .

\section{Results and Discussion}

The sandwich panels and the pressure-box test machine were modeled and analyzed for critical loading conditions to determine the panel response both with and without damage. Some of the analytical results are compared with the experimental results in this section.

\section{Undamaged panels results}

Combined 18.2 psi internal pressure and 1.110 lb/in. axial loading condition. This loading condition corresponds to twice the design limit pressure condition of 9 psi of internal pressure and a $1,110 \mathrm{lb} / \mathrm{in}$. load in the panel axial direction. The Panel 1 outer surface hoop and axial strain variations along the elliptical cutout edge obtained from the finite element analysis for this loading condition are presented in Figure 4. The hoop strain has the largest positive value at the edge of the elliptical cutout near the minor axis and the largest negative value along the major axis. The axial strain results in Figure 4(b) indicate a large positive strain value at the edge of the elliptical cutout at the ellipse major axis and a small negative value at the boundary of the cutout at its minor axis. The finite element analytical results in Figure 4 are consistent with the experimental results presented in Figure 5. The data points presented in Figure 5(a) and 5(b) correspond to strain gage locations indicated in Figure 5 (c) with $\theta=0^{\circ}, 30^{\circ}, 45^{\circ}, 60^{\circ}$, and $90^{\circ}$. For the panel outer surface, the measured axial strain values at the mi- nor axis is $-1,000 \mu \mathrm{in} / \mathrm{in}$. and the value at the major axis is $2,200 \mu \mathrm{in} / \mathrm{in}$. The finite element analytical results at the corresponding locations are $-662 \mu \mathrm{in} / \mathrm{in}$. and 1,420 $\mu \mathrm{in} / \mathrm{in}$, respectively. The analytical stress concentration factor for the axial stress is 3.01 for this loading condition.

The analytical strain results for Panel 2 for this loading condition are presented in Figure 6 . The trends for strain distribution are very similar to those for Panel 1, Panel 2 strains are lower than Panel 1 strains.

Combined 13.65 psi internal pressure and 2,450 $\mathrm{lb}$ /in. axial loading condition. This test condition corresponds to the design ultimate loading condition with 13.65 psi of internal pressure and $2,450 \mathrm{lb} / \mathrm{in}$. of axial loading. The Panel 1 outer surface hoop and axial strain results from the finite element analysis are presented in Figure 8. These analytical results suggest that the hoop strain has a small negative value along the cutout boundary at the ellipse's major axis and changes to a positive value at the ellipse's minor axis. The axial strain magnitudes are much larger than the hoop strains and are positive at the major axis and negative at the minor axis. The hoop and axial strain distributions from the experiment are presented in Figure 9. The trends of the experimental results agree extremely well with the finite element analytical results. The experimentally measured strains on the panel outer surface in the hoop direction vary from $1,150 \mu \mathrm{in} / \mathrm{in}$. to $-900 \mu \mathrm{in} / \mathrm{in}$. compared to the finite element analytical results which vary from $937 \mu \mathrm{in} / \mathrm{in}$. to $-949 \mu \mathrm{in} / \mathrm{in}$. In the axial direction, the measured strains vary from $4,000 \mu \mathrm{in} / \mathrm{in}$. to $-775 \mu \mathrm{in} / \mathrm{in}$. The corresponding results from the finite element analysis vary from $3,540 \mu \mathrm{in} / \mathrm{in}$. to $-815 \mu \mathrm{in} / \mathrm{in}$.

The analytical strain results for Panel 2 are presented in Figure 10. The axial loading condition for this panel was limited to $2,130 \mathrm{lb} / \mathrm{in}$. The trends for hoop and axial strain results agree with the results for Panel 1 very closely. The hoop strain magnitudes for Panel 2 are comparable to Panel 1 strains for this load condition, whereas the maximum value for the axial strain along the major axis of the elliptical cutout is smaller by a factor of 2. The difference in axial strain is due to the tapering in the region of the cutout Panel 2 to a laminate that has more $90^{\circ}$ plies than Panel 1.

Neither of the above two loading conditions resulted in strain magnitudes that exceed the strain allowables for the material systems used for manufacturing the test panels. There were no other indications from the experiment that suggested test panel failure. Further testing was conducted only on Panel 1 and it was assumed that the panel was in pristine condition at the end of all the previous tests. 


\section{Panel with the center frame removed}

The next set of loading conditions was imposed on Panel 1 with the center frame removed. The objective of these tests was to gather preliminary information on the sandwich panel response with a frame spacing increased to 40.0 inches. The frame was removed by severing the frame web above the frame attachment flange at the skin. The finite element analysis and experimental results corresponding to two loading conditions for this panel configuration are presented below.

Combined 18.2 psi internal pressure and 1,110 lb/in. axial loading condition. The finite element analytical results for this loading condition are presented in Figure 12. The hoop and axial surface strains are presented in the figure for the outer facesheet. The test was conducted by redistributing the loads in the severed frame to the remaining two frames to ensure that the panel was evaluated for the same load ratio of 80 and 20 percent of the load in the skin and the frames, respectively, for a given loading condition. The frame load for the panel with the two-frame configuration is greater than the frame load for the panel with the three-frame configuration. This increase in frame load is indicated by comparison of experimental results for the two-frame panel presented in Figure 13 with the results for the threeframe panel in Figure 5. The hoop strain in the remaining two frames increases by approximately 25 percent and the hoop strain in the skin between the two cutouts increases by approximately 12 percent due to the severing of the center frame. This increase in skin hoop strain is due to bending of the unsupported skin between the cutouts. The outer facesheet hoop strains from the experiment vary from approximately $-400 \mu \mathrm{in} / \mathrm{in}$. to $2,200 \mu \mathrm{in} /$ in. compared to the finite element results which vary from $-770 \mu \mathrm{in} / \mathrm{in}$. to $2,100 \mu \mathrm{in} / \mathrm{in}$. The axial strain results for this panel configuration corresponding to this loading condition are presented in Figure 13(b) and are very similar to those for the panel with a three-frame configuration.

Combined 13.65 psi internal pressure and 2.450 $\mathrm{lb} / \mathrm{in}$. axial loading condition. The panel outer surface hoop and axial strain results from finite element analysis are presented in Figure 14 for this loading condition. The overall observations for the axial and hoop strains for this loading condition are very similar to the previous loading condition for the two-frame panel. The experimental strain results for the two-frame panel are compared with the three-frame panel results in Figure 15. The maximum experimental axial strain along the cutout for the two-frame panel varies from $-850 \mu \mathrm{in} / \mathrm{in}$. to 4,000 $\mu$ in/in. compared to the analytical results which vary from $-540 \mu \mathrm{in} / \mathrm{in}$. to $3,860 \mu \mathrm{in} / \mathrm{in}$. These strain magnitudes are comparable to the axial strains for the threeframe panel for the same loading condition. Bending of the skin between the frames is also observed for this loading condition and is similar to that observed for the previous loading condition for the two-frame panel.

The panel with the two-frame configuration responds in a predictable manner and the strain magnitudes for this loading condition are well within the strain allowables for failure initiation.

Results for Panel 1 with no center frame and a notch at one cutout.

The final test case considered in the present study was Panel 1 with a center frame removed and a notch at one cutout. A maximum value for the undamaged test panel axial strain occurs at the edge of the elliptical cutout's major axis. The magnitude of the maximum strain is $4,000 \mu \mathrm{in} / \mathrm{in}$. for the combined 13.65 psi internal pressure and $2,450 \mathrm{lb} / \mathrm{in}$. axial loading condition. Damage in the form of a 1-in.-long saw-cut notch was inflicted at this critical location to study the damage tolerance of this sandwich panel concept with a combined-loading condition of $8.85 \mathrm{psi}$ internal pressure and $1,630 \mathrm{lb} / \mathrm{in}$. of axial load. This loading condition corresponds to $2 / 3$ of the design ultimate loading condition. The notch was machined into the panel to extend in the panel hoop direction slightly beyond the window frame edge. The panel outer surface hoop and axial strain results from the finite element analysis for this combinedloading condition are presented in Figure 16. The hoop strain for this loading condition varies from $-1,100 \mu \mathrm{in} /$ in. at $\theta=90^{\circ}$ to $1,900 \mu \mathrm{in} / \mathrm{in}$. at $\theta=0^{\circ}$ (Refer to Figure 5(c)). The strain magnitudes are higher for this loading condition than for the hoop strain results presented in Figure 14 for the combined loading condition with 13.65 psi of internal pressure and $2,450 \mathrm{lb} / \mathrm{in}$. of axial loading which are 66 percent lower. The notch causes more panel bending in the skin between the two cutouts in this test case, causing the increase in strain. The axial strain results from the finite element analysis for the outer surface indicate that a maximum strain of approximately $5,200 \mu \mathrm{in} / \mathrm{in}$. occurs at the tip of the machined notch. The experimental strain results for this load case are presented in Figure 17. The axial strain results vary from $-500 \mu \mathrm{in} / \mathrm{in}$. to $5,800 \mu \mathrm{in} / \mathrm{in}$. and compare very well with the analytical results. No growth in the notch length was observed during the test.

The experimental hoop strain results along the length for the three-frame panel, for the two-frame panel, and for the two-frame panel with a notch at the window cutout region are compared in Figure 18. These results 
along the $x$-axis suggest that the far field strains in the hoop direction are influenced more by the removal of the frame than by the introduction of the notch. The increase in the panel strain state due to the introduction of the notch is local and does not result in any significant load redistribution.

\section{Concluding Remarks}

The response of two composite sandwich fuselage side panels with two window cutouts has been evaluated for internal pressure and axial tension. The panels have been tested in a three-frame configuration with combined loading conditions that are representative of the design limit load and design ultimate load conditions. The strain magnitudes around the cutouts on the outer surfaces of the test panels for these loading conditions are within a value of $4,000 \mu \mathrm{in} / \mathrm{in}$. for the material, suggesting that the structure satisfies the design requirements. The finite element analytical results compare very well with the experimental results.

For a panel with a two-frame configuration, the finite element analysis and experimental results correlate well and the strain results are less than the ultimate strain allowables for the material. The damage tolerance of the panel with a two-frame configuration is also demonstrated by testing the panel at design limit load conditions with a notch at a window cutout region that is in the location of the highest value of axial stress. For this case, the maximum value for the axial strain obtained from the test and from the analysis is approximately $5,200 \mu \mathrm{in} / \mathrm{in}$. with no growth in the notch length. This result suggests that the panel with twice the original frame spacing is capable of sustaining the design ultimate load conditions without damage and of sustaining the design limit load conditions with a 1 -in.-long notch. This finding from the experiments is significant considering that reducing the number of frames results in a lighter weight structure. Based on the experimental results of both design concepts, lower stiffness at the window cutout area in Panel 2 design, considerably lower critical axial strains was observed than for the Panel 1 design. This provides a potential for optimizing Panel 2 design for weight.

\section{References}

1. Rouse, M.; and Ambur, D. R., "Evaluation of Damaged and Undamaged Fuselage Panel Responses Subjected to Internal Pressure and Axial Load," Sixth NASA/DoD/ARPA ACT Conference, Anaheim, CA, August 7-11, 1995.

2. Rouse, M., and Ambur, D. R., 'Fuselage Response Simulation of Stiffened Panels Using a Pressure-box Test Machine," AIAA-95-1362-CP, April 1995.

3. Anon., "ABAQUS Finite Element Code," Hibbitt, Carlson and Sorenson, Inc., Vol. 1-2, 1995.

Table 1: Typical material properties for the graphite-epoxy materials used to manufacture the sandwich panel.

\begin{tabular}{lcccc}
\hline \hline Property & Tow AS4/8552 & $\begin{array}{c}\text { Fabric } \\
\text { AS4/8552 }\end{array}$ & $\begin{array}{c}\text { Triaxial braid } \\
\text { AS4/PR500 }\end{array}$ & $\begin{array}{c}\text { Korex core } \\
4.5 \mathrm{lb}, 1 / 8 \text { in. cell }\end{array}$ \\
\hline Longitudinal Modulus, $\mathrm{E}_{1}$ (Msi) & 18.30 & 9.20 & 7.50 & 0.0001 \\
Longitudinal Modulus, $\mathrm{E}_{2}(\mathrm{Msi})$ & 1.36 & 9.20 & 7.5 & 0.00001 \\
Lateral modulus, $\mathrm{E}_{3}$ (Msi) & 1.36 & 1.30 & $-\cdots$ & 0.0340 \\
$\begin{array}{l}\text { In-plane shear modulus, } \mathrm{G}_{12} \\
\text { (Msi) }\end{array}$ & 0.76 & 0.72 & 0.57 & 0.00001 \\
$\begin{array}{l}\text { Transverse shear modulus, } \mathrm{G}_{23} \\
\text { (Msi) }\end{array}$ & 0.52 & 0.50 & 0.40 & 0.0136 \\
$\begin{array}{l}\text { Transverse shear modulus, } \mathrm{G}_{23} \\
\text { (Msi) }\end{array}$ & 0.76 & 0.50 & 0.57 & 0.0326 \\
Major Poisson's ratio, $\mathrm{v}_{12}$ & 0.32 & 0.04 & 0.29 & 0.30 \\
\hline \hline
\end{tabular}




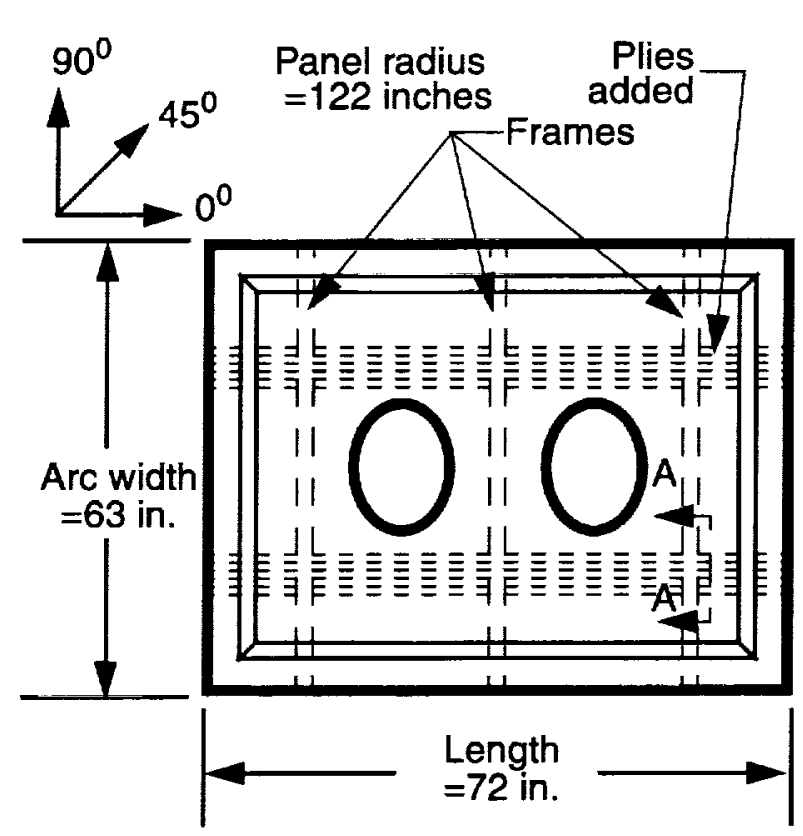

a. Plan view of the panel.

Figure 1. Construction details for the sandwich panels through Section AA.

\section{f - fabric}

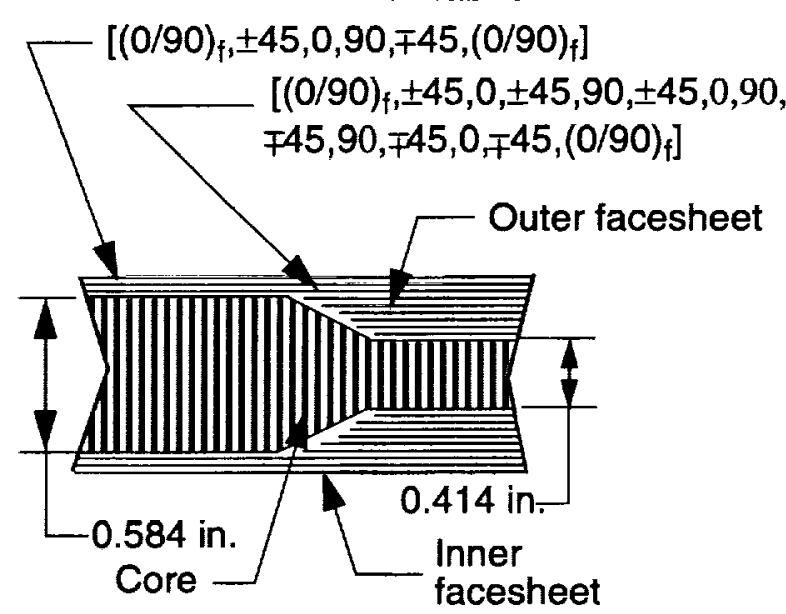

b. Panel 1 cross-sectional view.

Figure 1.
Continued.

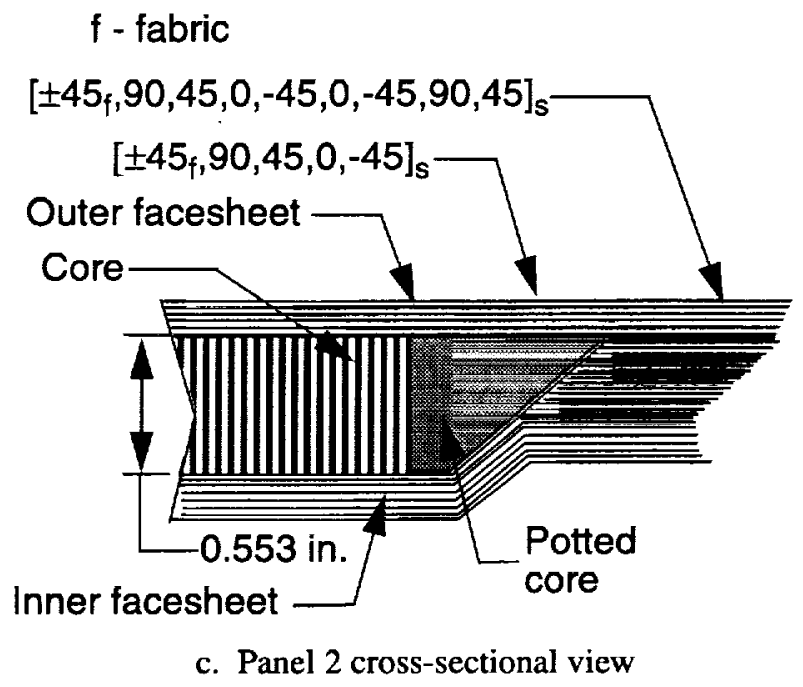

Figure 1. Concluded.

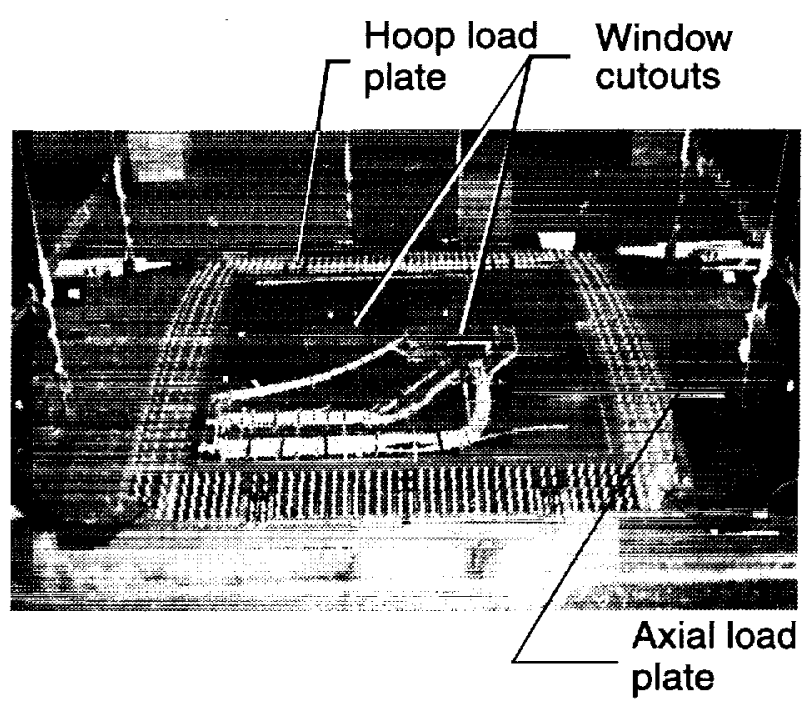

Figure 2. Photograph of a typical sandwich panel assembly. 


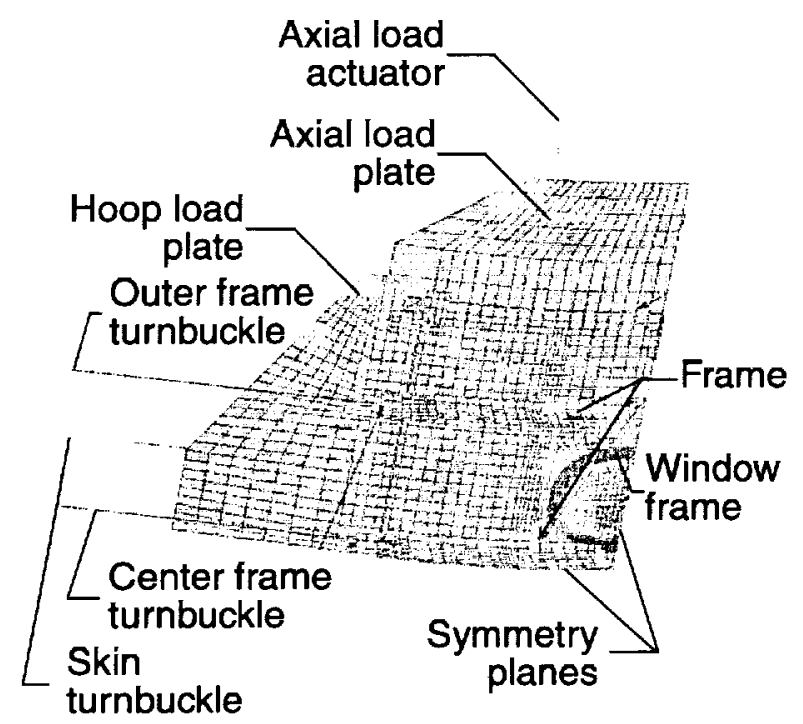

Figure 3. Finite element model of a sandwich panel.

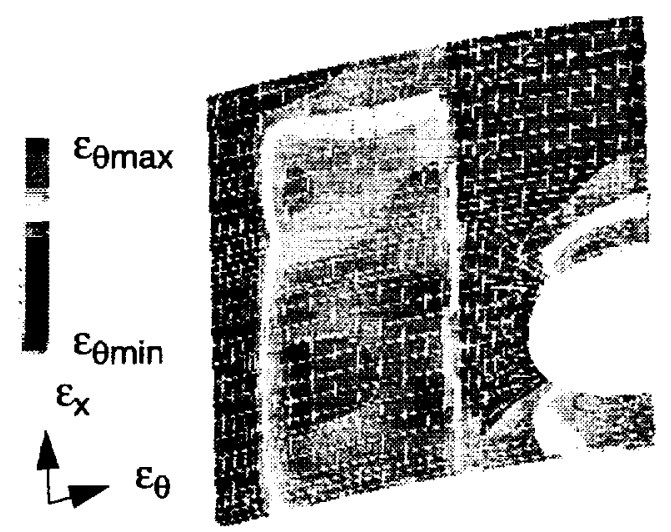

a. Hoop Strain

Figure 4. Finite element analytical results for Panel 1 (three-frame) outer surface for a combined $18.2 \mathrm{psi}$ internal pressure and $1,110 \mathrm{lb} / \mathrm{in}$. axial loading condition.

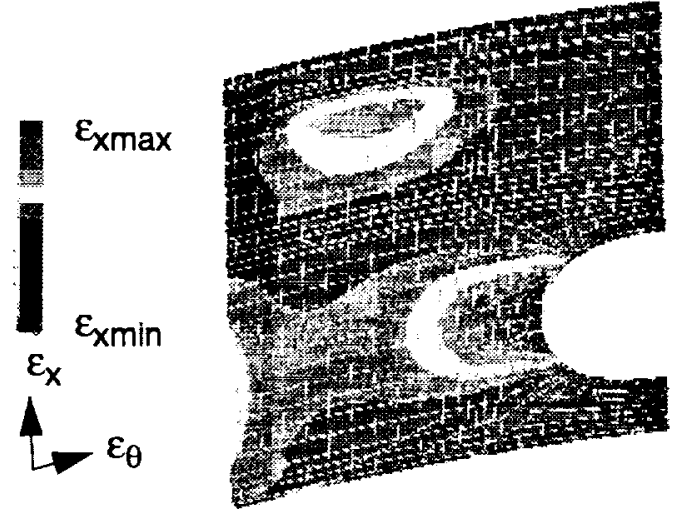

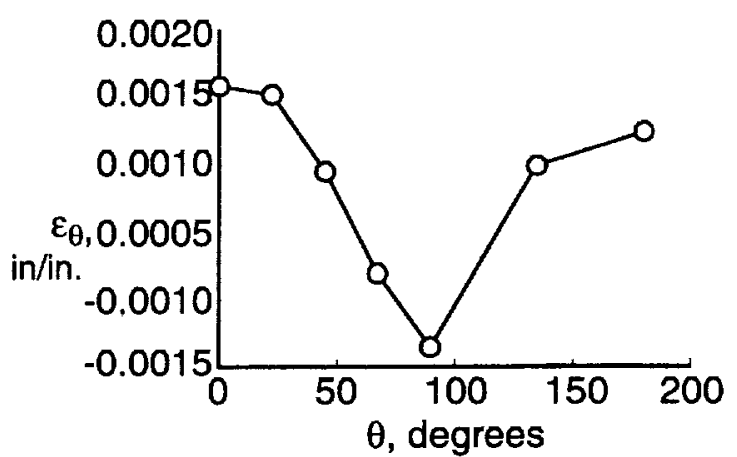

\section{a. Hoop strain}

Figure 5. Experimental strain results for Panel 1 (three-frame) outer surface for a combined $18.2 \mathrm{psi}$ internal pressure and $1,110 \mathrm{lb} / \mathrm{in}$. axial loading condition.

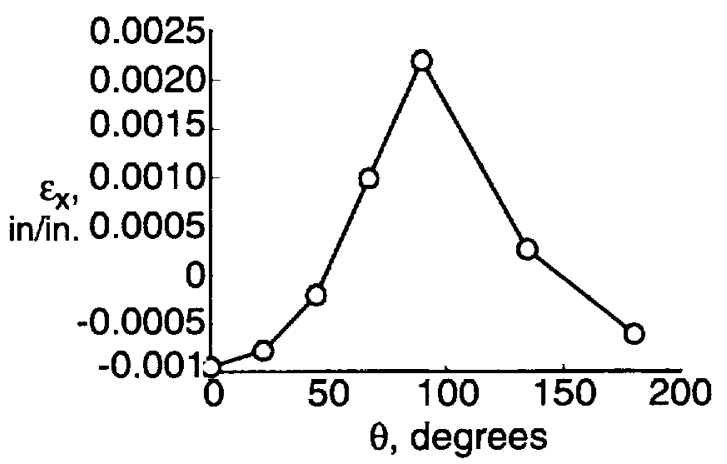

b. Axial strain

Figure 5. Continued.

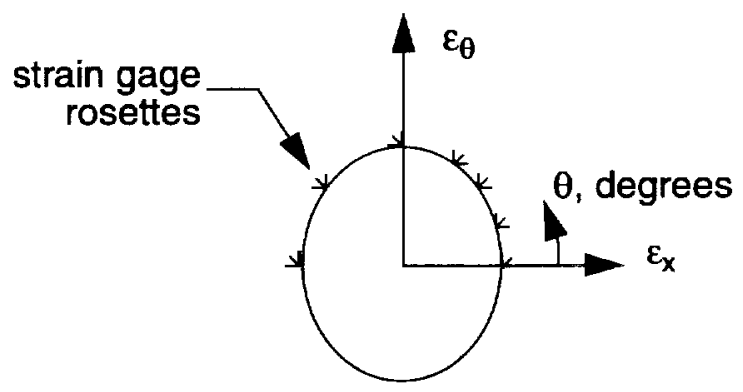

\section{c. Strain gage locations}

Figure 5. Concluded.

Figure 4. Concluded. 


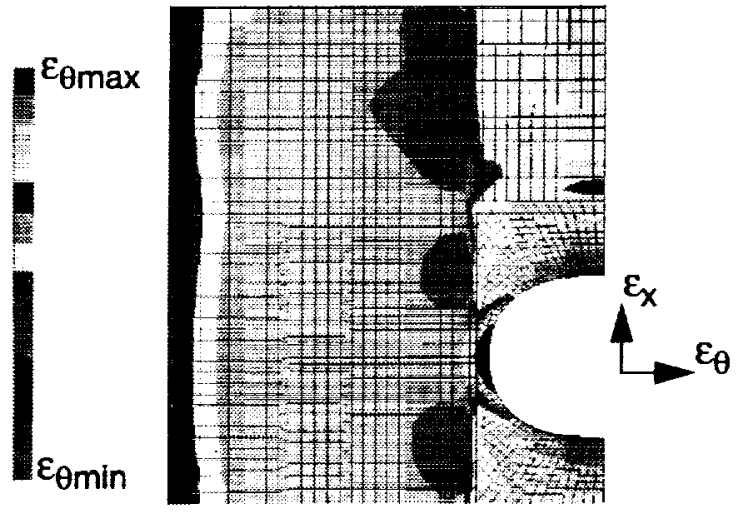

a. Hoop strain

Figure 6. Finite element analytical results for Panel 2 (three-frame) outer surface for a combined $18.2 \mathrm{psi}$ internal pressure and 1,110 lb/in. axial loading condition

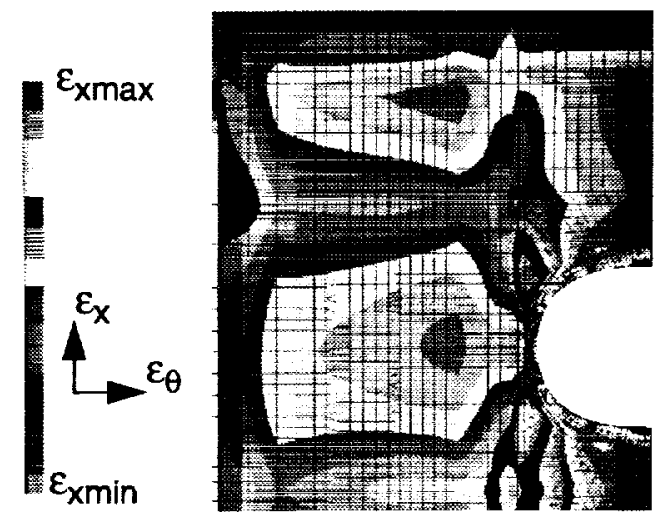

b. Axial strain

Figure 6. Concluded.

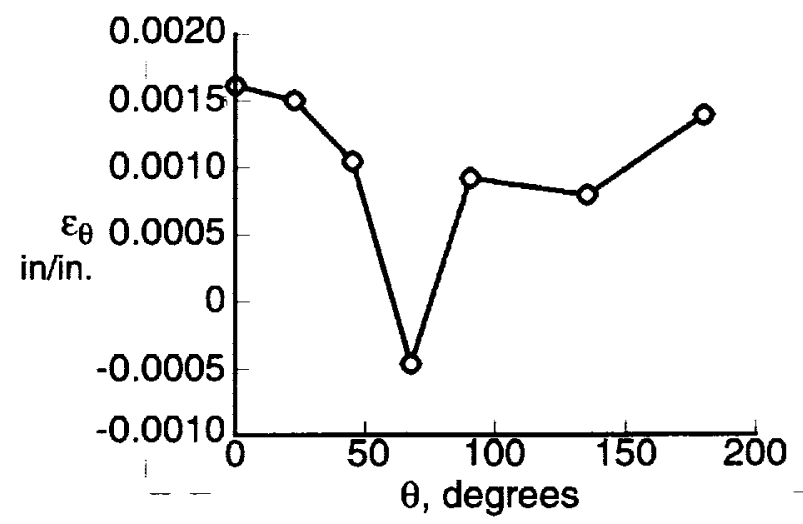

a. Hoop strain

Figure 7. Experimental strain results on Panel 2 (three-frame) outer surface for a combined $18.2 \mathrm{psi}$ internal pressure and $1,110 \mathrm{lb} / \mathrm{in}$. axial loading condition.

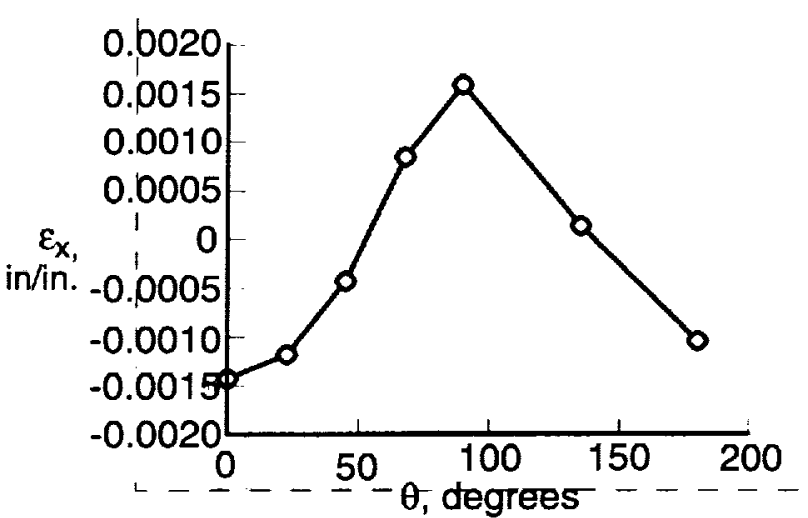

b. Axial strain

Figure 7. Concluded.

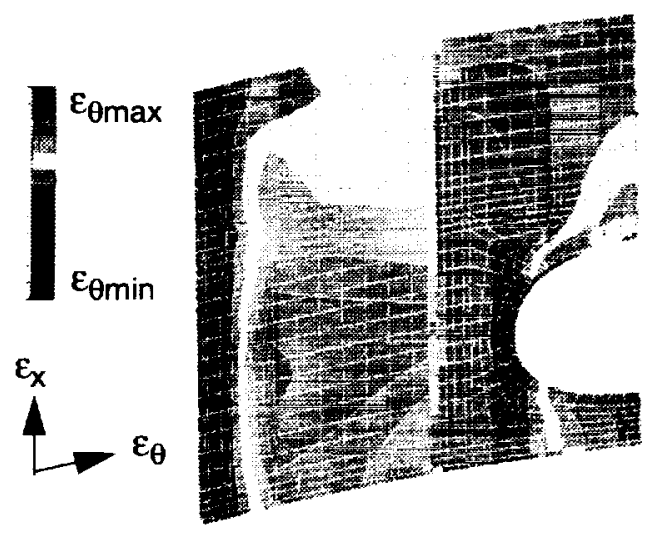

a. Hoop strain

Figure 8. Panel 1 finite element analytical results for Panel 1 (three-frame) outer surface for a combined 13.65 psi internal pressure and $2,450 \mathrm{lb} / \mathrm{in}$. axial loading condition

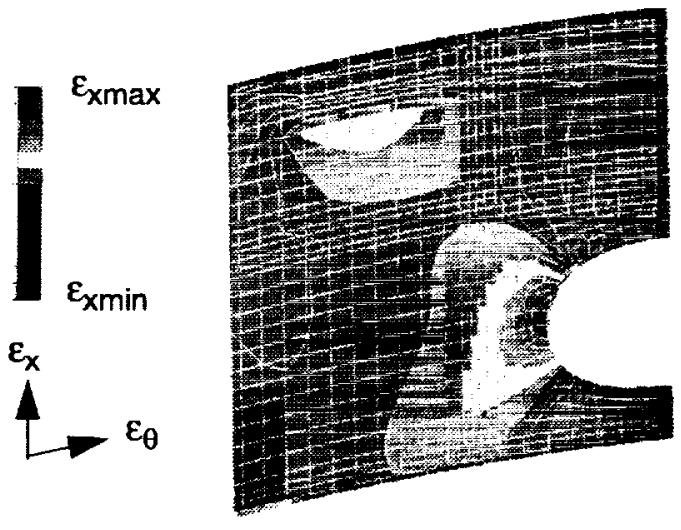

b. Axial strain

Figure 8. Concluded. 


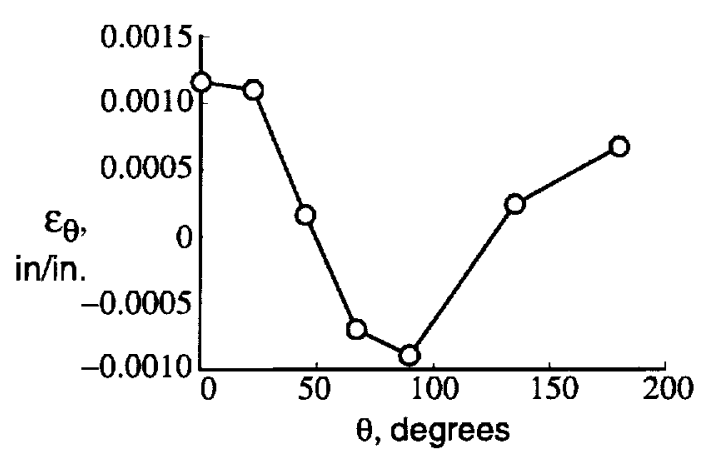

a. Hoop strain

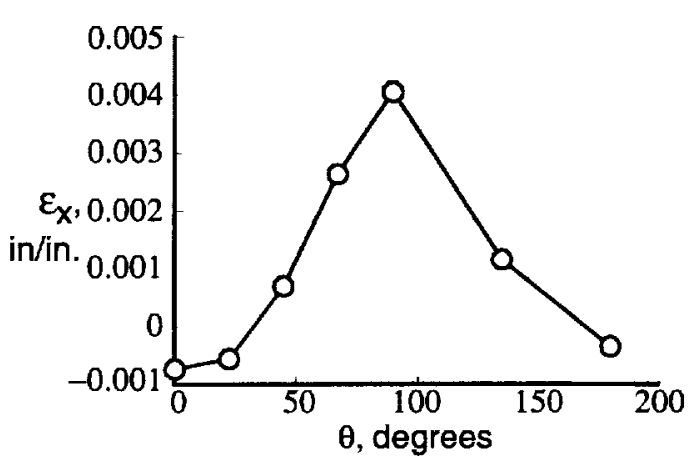

b. Axial strain

Figure 9. Experimental strain results Panel 1 (threeframe) for a combined $13.65 \mathrm{psi}$ internal pressure and $2,450 \mathrm{lb} / \mathrm{in}$. axial loading condition.
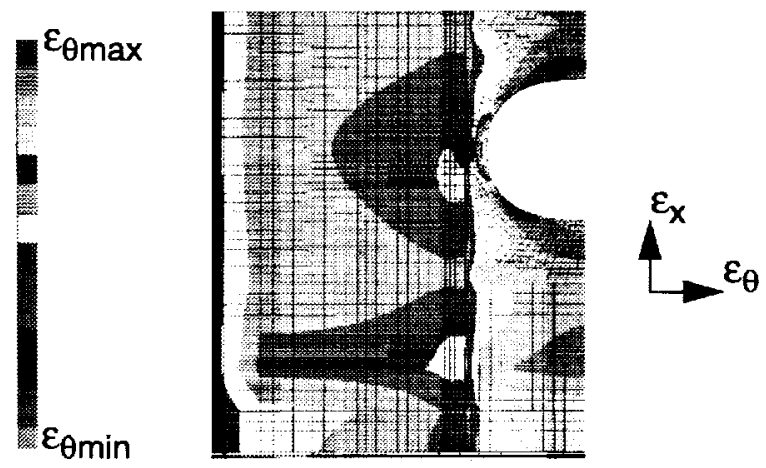

a. Hoop strain

Figure 10. Finite element analytical results for Panel 2 (three-frame) outer surface for a combined $13.65 \mathrm{psi}$ internal pressure and $2,130 \mathrm{lb} / \mathrm{in}$. axial loading condition.

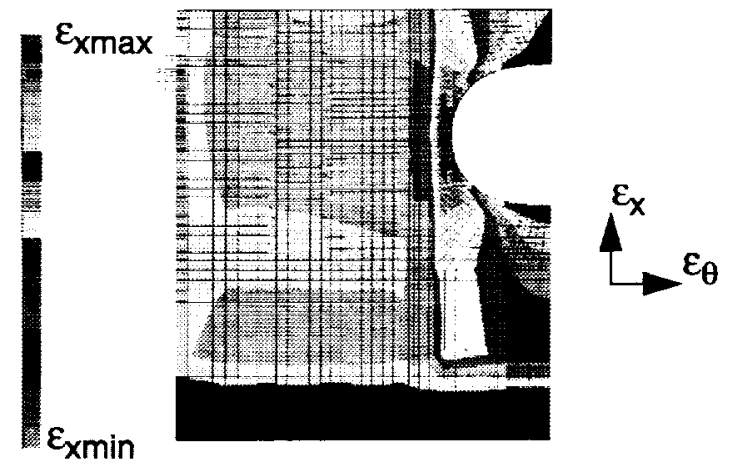

b. Axial strain

Figure 10. Concluded.

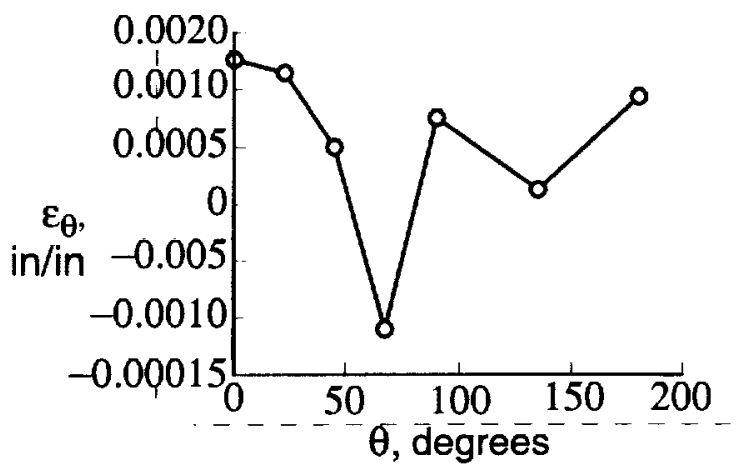

a. Hoop strain

Figure 11. Experimental strain results for Panel 2 (three-frame) outer surface for a combined $13.65 \mathrm{psi}$ internal pressure and $2,450 \mathrm{lb} / \mathrm{in}$. axial loading condition

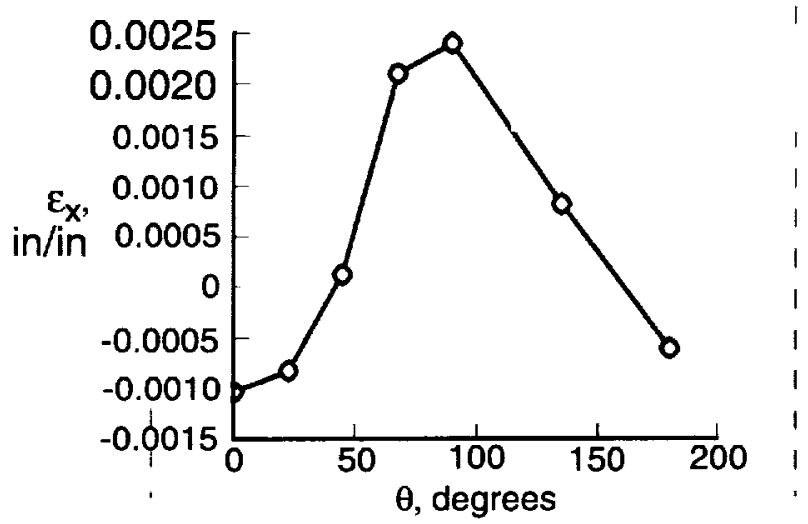

b. Axial strain

Figure 11. Concluded. 


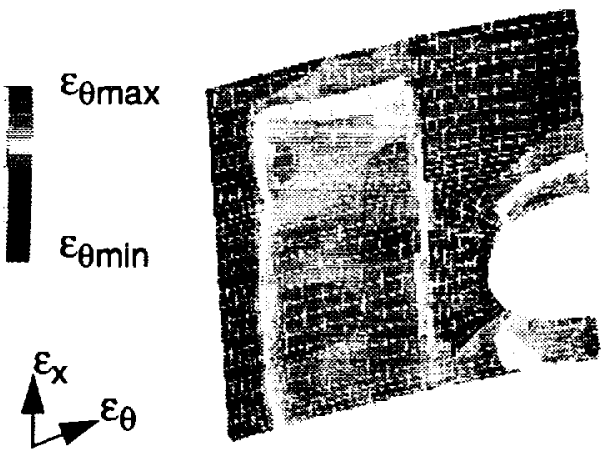

a. Hoop strain

Figure 12. Finite element analytical results for Panel 1 (two-frame) outer surface for a combined $18.2 \mathrm{psi}$ internal pressure and $1,110 \mathrm{lb} / \mathrm{in}$. axial loading condition.

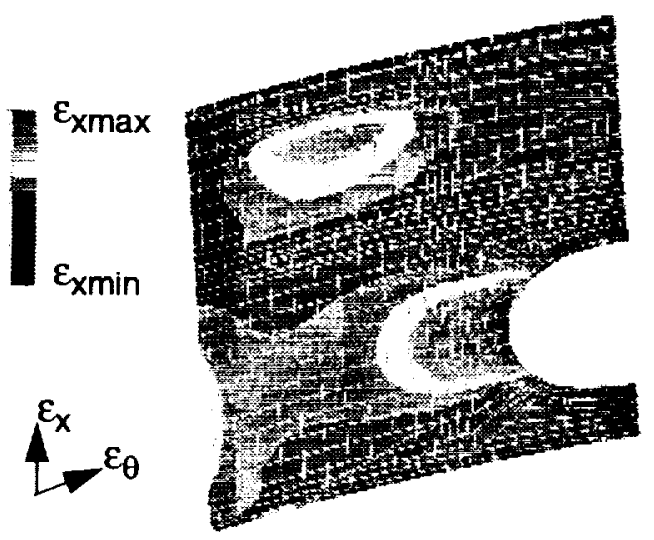

b. Axial strain

Figure 12. Concluded.

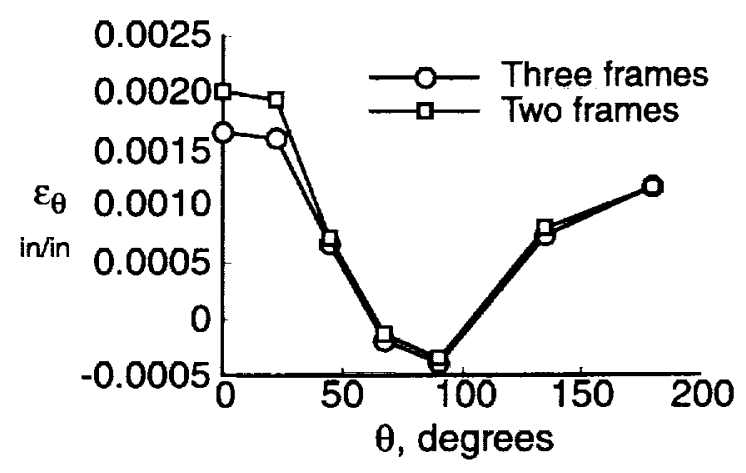

a. Hoop strain

Figure 13. Experimental strain results for Panel 1 (two-frame) outer surface for a combined 18.2 psi internal pressure and $1,110 \mathrm{lb} / \mathrm{in}$. axial loading condition.

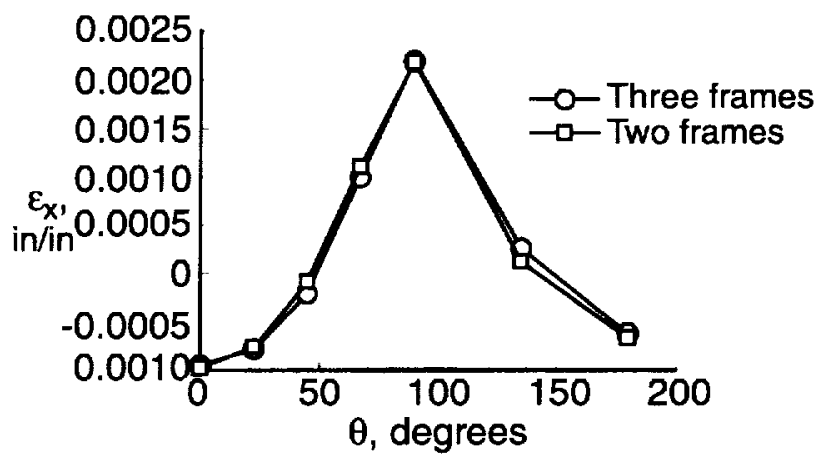

b. Axial strain

Figure 13. Concluded.

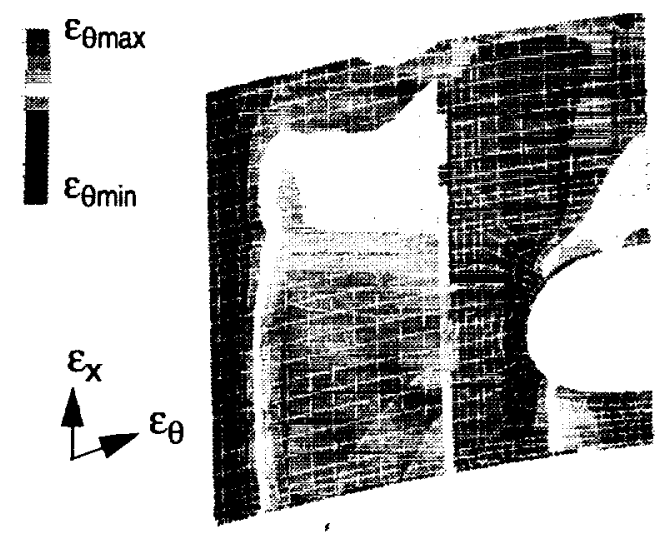

a. Hoop strain

Figure 14. Finite element analytical results for Panel 1 (two-frame) outer surface for a combined $13.65 \mathrm{psi}$ internal pressure and $2,450 \mathrm{lb} / \mathrm{in}$. axial loading condition

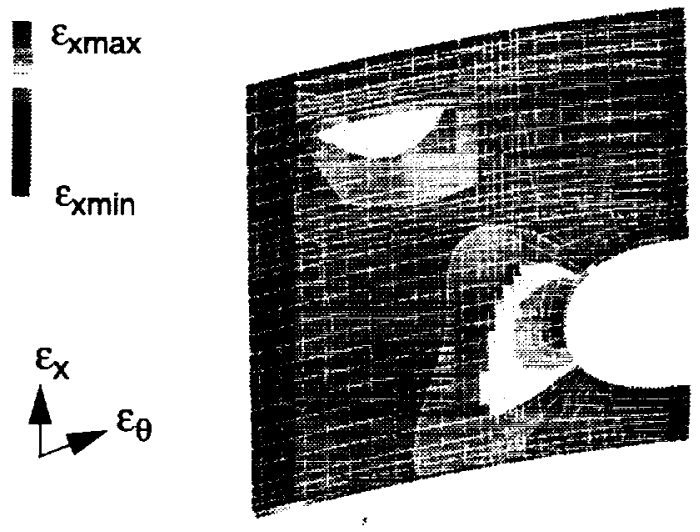

b. Axial strain

Figure 14. COncluded. 


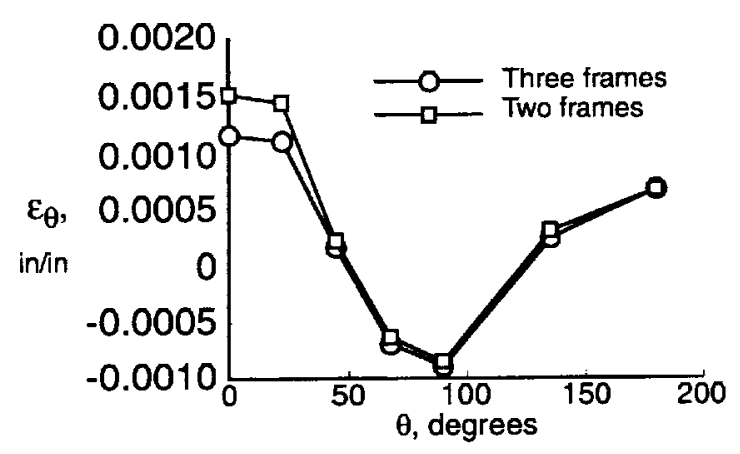

a. Hoop strain

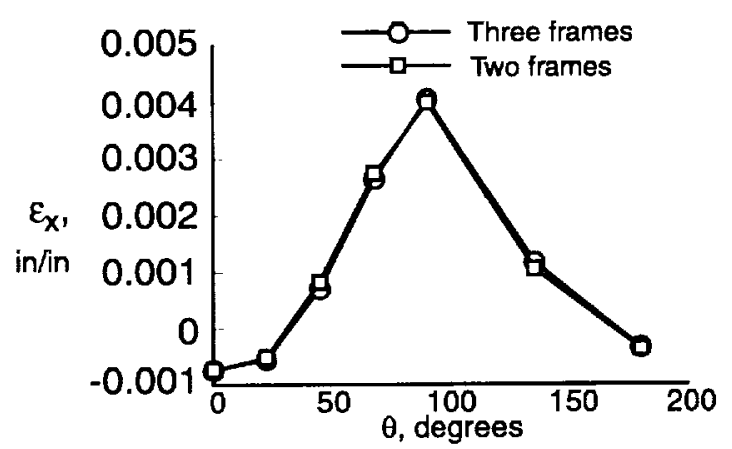

b. Axial strain

Figure 15. Experimental strain results for Panel 1 (two-frame) outer surface for a combined $13.65 \mathrm{psi}$ internal pressure and $2,450 \mathrm{lb} / \mathrm{in}$. axial loading condition.

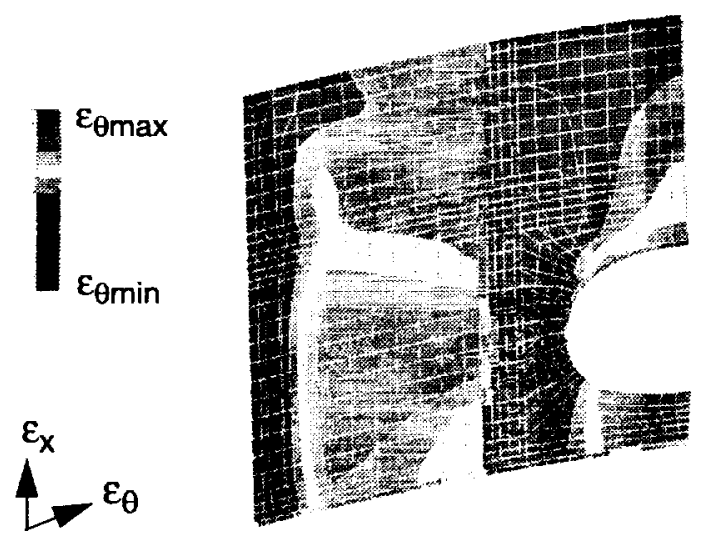

a. Hoop strain

Figure 16. Finite element analytical results for the notched two-frame panel (Panel 1) outer surface for a combined 8.85 psi internal pressure and 1,630 lb/in. axial loading condition.

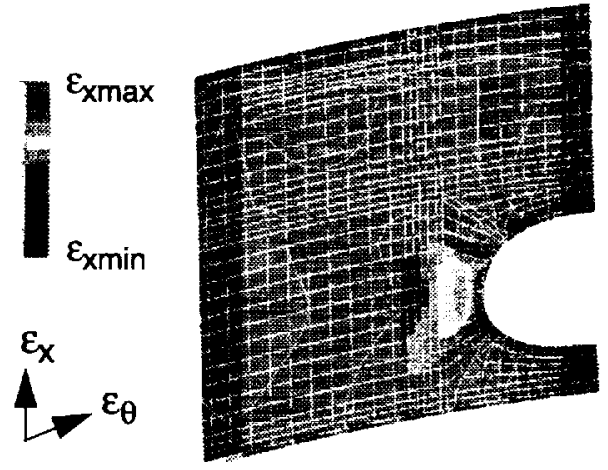

b. Axial strain

Figure 16. Concluded.

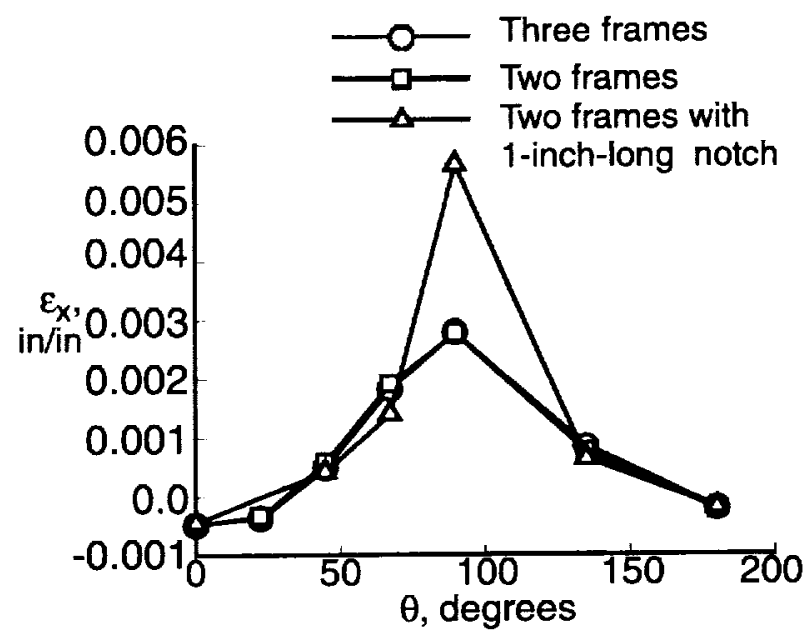

Figure 17. Experimental axial strain results for the notched two-frame panel (Panel 1) outer surface for a combined 8.85 internal pressure and $1,630 \mathrm{lb} / \mathrm{in}$. axial loading condition.

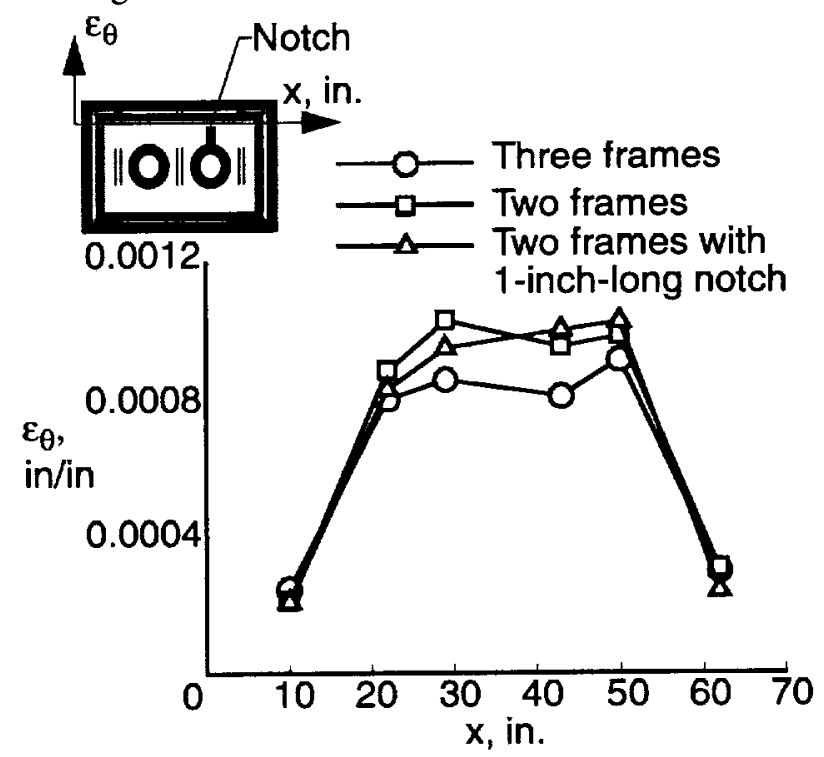

Figure 18. Comparison of experimental far-field outer surface hoop strain results for Panel 1 with three-frames, two-frames, and two-frames with a notch. 
